\title{
Synaptosomes: new vesicles for neuronal mitochondrial transplantation
}

\author{
Pasquale Picone ${ }^{1}$ [D, Gaetana Porcelli ${ }^{1}$, Celeste Caruso Bavisotto ${ }^{2,3,4}$, Domenico Nuzzo ${ }^{1}$, Giacoma Galizzi' \\ Pier Luigi San Biagio ${ }^{2}$, Donatella Bulone ${ }^{2}$ and Marta Di Carlo ${ }^{1 *}$ (D)
}

\begin{abstract}
Background: Mitochondrial dysfunction is a critical factor in the onset and progression of neurodegenerative diseases. Recently, mitochondrial transplantation has been advised as an innovative and attractive strategy to transfer and replace damaged mitochondria. Here we propose, for the first time, to use rat brain extracted synaptosomes, a subcellular fraction of isolated synaptic terminal that contains mitochondria, as mitochondrial delivery systems.

Results: Synaptosome preparation was validated by the presence of Synaptophysin and PSD95. Synaptosomes were characterized in terms of dimension, zeta potential, polydispersity index and number of particles/ml. Nile Red or CTXFITCH labeled synaptosomes were internalized in LAN5 recipient cells by a mechanism involving specific proteinprotein interaction, as demonstrated by loss of fusion ability after trypsin treatment and using different cell lines. The loading and release ability of the synaptosomes was proved by the presence of curcumin both into synaptosomes and LAN5 cells. The vitality of mitochondria transferred by Synaptosomes was demonstrated by the presence of Opa1, Fis1 and TOM40 mitochondrial proteins and JC-1 measurements. Further, synaptosomes deliver vital mitochondria into the cytoplasm of neuronal cells as demonstrated by microscopic images, increase of TOM 40, cytochrome c, Hexokinase II mitochondrial proteins, and presence of rat mitochondrial DNA. Finally, by using synaptosomes as a vehicle, healthy mitochondria restored mitochondrial function in cells containing rotenone or CCCp damaged mitochondria.
\end{abstract}

Conclusions: Taken together these results suggest that synaptosomes can be a natural vehicle for the delivery of molecules and organelles to neuronal cells. Further, the replacement of affected mitochondria with healthy ones could be a potential therapy for treating neuronal mitochondrial dysfunction-related diseases.

Keywords: Synaptosomes, Mitochondria, Neurodegeneration, Delivery system, Mitochondrial transplantation

\section{Background}

Neurodegenerative diseases (NDs) are debilitating agerelated disorders characterized by progressive loss of structural and functional neurons. It has been estimated that approximately 30 million people worldwide are affected by NDs and the number is expected to exceed 150 million in 2050 [1]. The lack of any effective treatment

*Correspondence: marta.dicarlo@irib.cnr.it

${ }^{1}$ Istituto per la Ricerca e I'Innovazione Biomedica (IRIB) CNR, via U. La Malfa 153, 90146 Palermo, Italy

Full list of author information is available at the end of the article makes these pathologies a significant public health issue. NDs are characterized by the accumulation of aggregates of misfolded proteins in specific areas of the brain and they include Alzheimer's disease (AD), Parkinson's disease (PD), and Huntington's disease (HD) [1]. These pathologies are known to be multifactorial disorders, but one of the most accepted assumptions is that mitochondrial dysfunction is a critical factor in their onset and progression [1-4]. Mitochondria are the primary source of energy metabolism and play a relevant role in several cell functions such as calcium homeostasis, reactive oxygen species (ROS) production, cell survival and proliferation, 
control of apoptosis and autophagy [3]. Mitochondria are dynamic organelles capable of changing size, shape, and position according to the cells' physiological needs. They move along microtubules within the cell, providing the energy for the different cells' activities, including the synaptic ones. Mitochondrion wellness is crucial for cellular homeostasis and its impairment is linked to several neurodegenerative diseases. Mitochondrial dysfunction is associated with altered antioxidant defence or excessive ROS generation. The use of natural antioxidants as potential therapeutic molecules for the prevention and treatment of NDs has been largely explored $[4,5]$ Antioxidants such as resveratrol, green tea polyphenol, epigallocatechin gallate (EGCC) or ferulic acid were found to exert beneficial effects both on in vitro and in vivo models of NDs [6-9]. Although quite controversial, some studies in humans report that the administration of highdose combined vitamin $E$ and vitamin $C$ is associated with a slowed progression of PD. Further, the beneficial effect can be improved by encapsulating the antioxidant molecules into nanoparticles capable of enhancing drug transport through the Blood Brain Barrier (BBB) [10, 11]. Studies in vitro reported that insulin could prevent mitochondrial oxidative stress and apoptosis by inhibiting the PI3K/AKT cell survival signaling pathway, similarly to what was also observed for antioxidant molecules $[12,13]$. Recent evidence has demonstrated that insulin delivery to the brain can be an effective pharmacological therapy for some neurodegenerative pathologies, and the intranasal route can further increase the efficacy and safety of the treatment [14].

Unfortunately, all these strategies to contrast mitochondrial stress are not considered yet effective prevention or therapy for NDs, and the possibility to replace damaged mitochondria results in being extremely attractive.

Mitochondria have a life cycle in which mitochondrial dynamics and mitophagy contribute to quality control. The dynamics of mitochondria is regulated by fusion and fission events. These mechanisms are controlled by specific proteins such as mitofusin 1 (MNF1) and optic atrophy protein 1 (OPA1) for fusion, and dynamin-related protein-1 (Drp1) and fission1 (FIS1) for fission [15]. When mitochondria are damaged, the organelles can be recovered by fusing with healthy mitochondria or eliminated by mitophagy. However, when damaged mitochondria cannot be replaced or restored, the possibility to transfer healthy mitochondria from one cell to another represents an attractive therapeutic strategy. Currently, the transfer of "alive" mitochondria into injured cells takes the name of mitochondrial transplantation and it is becoming a popular approach for the treatment of several diseases, including NDs [16-19].
Some strategies such as direct microinjection of isolated mitochondria, cell-mediated transfer utilizing tunneling nanotubes, vesicle- or liposome-mediated delivery, and systemic delivery have been evaluated to ameliorate mitochondria uptake and transplantation efficiency [19]. Nevertheless, adverse effects such as inflammatory or immune response due to the introduction of cellular elements with mitochondria can interfere with the transplantation efficacy [19]. Instead, an increased incorporation efficiency was observed when isolated mitochondria from a healthy individual were conjugated with the carrier peptide Pep-1 [20]. However, delivery approaches have to be optimized based on the tissue or cell type.

Synaptosomes are a subcellular fraction isolated from synaptic terminals that can be prepared by homogenization and gradient centrifugation of brain tissue. The term "synaptosome" was coined by Whittaker (1964) [21], who studied the localization of neurotransmitters and the functional components of the synapses. Synaptosomes contain numerous synaptic vesicles and mitochondria and are considered a relevant model system for studying human synaptic dysfunction in NDs [22]. Although the use of cells or cell membrane-based drug delivery systems has been investigated [23, 24], the possibility of using a subcellular structure for organelle delivery has not been studied yet.

For the first time, we propose using a synaptosomebased mitochondria delivery system to transfer healthy mitochondria to neuronal target cells. Furthermore, we evaluated the possibility of replacing CCCp- or rotenonedamaged mitochondria in neuronal cells by synaptosomes transplantation.

\section{Results}

\section{Isolation and characterization of rat synaptosomes}

Synaptosomes, extracted from the pre- and post-synaptic components (Fig. 1a), were isolated by sucrose density gradient ultracentrifugation of the fresh rat brain homogenate. The presence of synaptosomes in the collected band (Fig. 1b) was ascertained by detecting with Western blot experiments the presence of two specific pre-synaptic and post-synaptic markers, Synaptophysin and PSD95, respectively (Fig. 1c). A significant content of these two proteins was found in the collected band with respect to the total homogenate (Fig. 1c, d), confirming the fractionation procedure's success. By Dynamic Light Scattering (DLS) measurements, the synaptosomes' size was determined to range between 0.5 and $1.5 \mu \mathrm{m}$ with a mean diameter of about $800 \mathrm{~nm}$ (Fig. 1e). AFM images (Fig. 1f) demonstrated the typical synaptosomes features, confirming the heterogeneity of the preparation. The synaptosomes fraction was also characterized in terms of zeta potential, polydispersity index (PDI), concentration. The values are reported in Table 1. 


\section{Synaptosomes cell interaction and uptake}

Synaptosomes are membranous sacs composed of a lipid bilayer, including lipid rafts [25] and synaptic components. Intending to use them as delivery systems, firstly, we investigated if synaptosomes were toxic to LAN5 neuronal cells (Additional file 1: Fig. S1). Synaptosomes were incubated with the membrane staining Nile Red (red), or with the lipid raft staining CTX (green). Results from fluorescence measurements (Fig. 2a, b) showed that both the dyes were suitable for staining the synaptosomes and, therefore, as vesicle tracing. LAN5 cells were incubated with different amounts of synaptosomes stained with Nile Red (red) or CTX-FITC (green), and the fluorescence signal was measured to evaluate cellular uptake of synaptosomes (Fig. 2c). The fluorescence intensity was observed to increase in a dose-dependent manner for both the tracker dyes (Fig. 2d, f). The interaction between synaptosomes and LAN5 was also visualized by fluorescence microscopy inspection (Fig. 2e, g). LAN5 uptake of synaptosomes was furtherly evidenced by detecting the presence of rat synaptophysin, a presynaptic protein associated with synaptic vesicles and presynaptic membrane [26]. After administering different amounts of synaptosomes to LAN5 cells, the presence of the rat synaptophysin was investigated (Fig. 2h). Western blot experiments on LAN5 extracted confirmed the presence of a band of about $36 \mathrm{kDa}$ corresponding to rat synaptophysin (Fig. 2i). This band intensity was higher at larger administered doses of synaptosomes (Fig. 2i, 1). A higher band of $45 \mathrm{kDa}$ with the same intensity, representing the human endogenous protein, was also observed (Fig. 2i). As the trypsin treatment used in protein extraction removes synaptosomes interacting with the cellular surface, it is reasonable that the detected rat synaptophysin was due to internalization of synaptosomes or fusion of membranes.

\section{Synaptosomes as a potential delivery system}

The ability of synaptosomes to release the cargo was tested by using curcumin, a fluorescent compound derived from the rhizome of Curcuma longa. It had been shown that curcumin could be loaded into lipid nanosystems and internalized in neuronal cells [27]. After curcumin addition to synaptosomes (Fig. 3a) an increase of the fluorescence intensity was observed, indicating that synaptosomes were able to incorporate curcumin. Different amounts of curcumin-loaded synaptosomes (Synap-Curcumin) were then incubated with LAN5 cells for 2 and $4 \mathrm{~h}$ (Fig. $3 \mathrm{~b}$ ). An enhancement of fluorescence intensity was observed in the

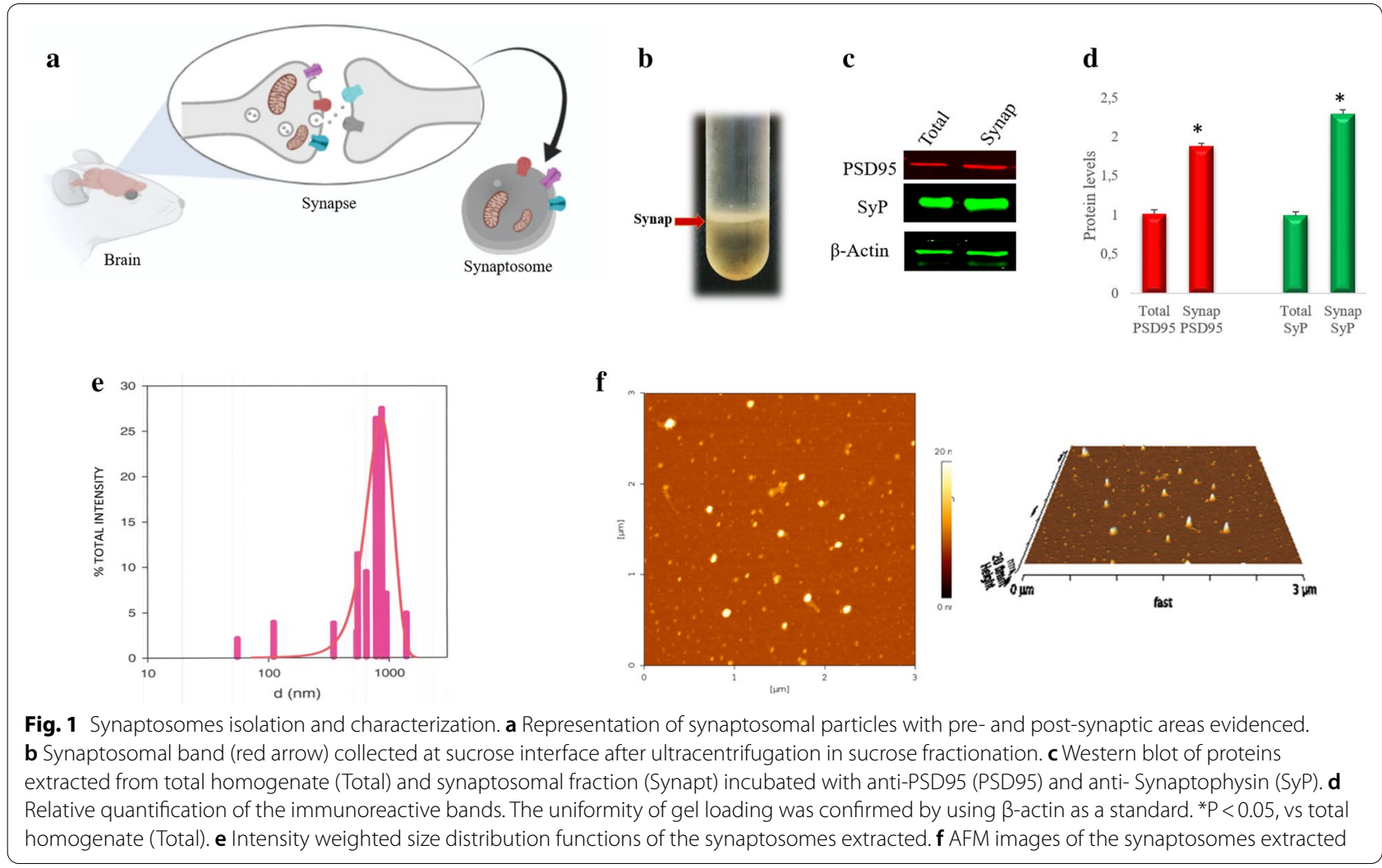


sample treated with $20 \mu \mathrm{l}$ of curcumin-loaded synaptosomes, especially after $4 \mathrm{~h}$ of incubation (Fig. 3c). The results were confirmed by microscopy images (Fig. 3d). Green fluorescence was observed in the cellular body, confirming that the compound was released by the synaptosomes inside the cells (Fig. 3d).

\section{Synaptosomes-specific cell interaction}

Nile red-stained synaptosomes were treated with two different amounts of trypsin (Fig. 4a) and incubated with LAN5 cells in order to inspect whether the contact between synaptosomes and the cell membrane is due to protein-protein and/or lipid-protein interaction. The fluorescence intensity for cells incubated with synaptosomes treated with trypsin was found lower than that for cells incubated with untreated synaptosomes (Fig. 4b). Microscopic images of Fig. 4c confirmed this result. Here, the red signal that indicates interaction between cells and synaptosomes is significantly lower in the case of trypsin treated synaptosomes. This outcome suggests that some proteins disrupted by the trypsin treatment could play a relevant role in synaptosomes cellular uptake. Furthermore, two amounts of Nile redstained synaptosomes were administered to different cell lines, including neuronal (LAN5), epithelial (A549) and hepatic (HepG2) cells, to assess if cellular interaction and uptake of synaptosomes are neuron-specific. By microscopy imaging (Fig. 4d) and fluorescence measurements (Fig. 4e) we observed no significant fluorescence signal for both A549 and HepG2 cells, while fluorescence

Table 1 Concentration (particles/ml), zeta potential and polydispersity index of extracted synaptosomes

\begin{tabular}{ll}
\hline Synaptosome parameters & \\
\hline [Particles/m1] & $5.1 \times 10^{9} \pm 0.7 \times 10^{9}$ \\
Zeta Potential $[\mathrm{mV}]$ & $-43.5+5$ \\
polydispersity & 0.307 \\
\hline
\end{tabular}

signals were detected in LAN5 cells. This evidence can suggest that specific neuronal proteins are necessary for synaptosomes-cell interaction and uptake.

\section{Synaptosomes transport vital mitochondria that can be cryopreserved}

Synaptosomes contain synaptic vesicles and often one or more mitochondria. Mitochondria presence and viability in isolated synaptosomes were analyzed. The presence of mitochondrial specific proteins including the protein optic atrophy 1 (Opa1) (inner mitochondrial membrane protein), Fission 1 protein (Fis1) (outer mitochondrial membrane proteins) and Translocase of Outer Mitochondrial Membrane 40 (TOM40) in synaptosomal preparation was investigated by Western blotting analysis. The three proteins were detected in synaptosomal fractions, meaning that synaptosomes contain mitochondria (Fig. 5a). This result was also confirmed by staining synaptosomes with JC1, a fluorescent dye that emits red fluorescence when the mitochondrial membrane potential is high and mitochondria are healthy (Fig. 5b). To further validate the presence of mitochondria, synaptosomes were treated with CCCp, an inhibitor of oxidative phosphorylation. A drastic reduction of red fluorescence was observed in this case (Fig. 5b). Representative fluorescence images for all samples are shown in Fig. 5c. Thus, synaptosome preparation contains functional mitochondria.

Finally, we evaluated their physical-chemical properties and biological activity to test whether cryopreserved synaptosomes can be used for mitochondrial transplantation. Rat cerebral cortex synaptosomes preparation was frozen under controlled temperature steps and times (Fig. 5d). After thawing, physical parameters such as dimensions and zeta potential were measured and compared with those of fresh synaptosomes. No significant difference was detected (Fig. 5e). The viability of mitochondria, after freeze/thawing of synaptosomes, was assessed by JC-1 fluorescence assay. The results showed that the red and green fluorescence of the thawed synaptosomes was comparable to that of fresh synaptosomes

\footnotetext{
(See figure on next page.)

Fig. 2 Synaptosomes can interact with cells. a Histogram of fluorescence intensity and fluorescence image of synaptosomes stained with Nile Red (Synap Nile Red) and related cartoon. b Histogram of fluorescence intensity and fluorescence image of synaptosomes stained with CTX-FITC (Synap CTX-FITC) and related cartoon. c Cartoon of neuronal cells incubated with synaptosomes stained with Nile Red or CTX-FITC. $\mathbf{d}$ Histogram of fluorescence intensity of LAN5 cells incubated with different doses of synaptosomes labeled with Nile Red (Synap Nile Red 5-10 and 20 ul). e Representative fluorescence images of Synap NileRed and LAN5 cells interaction, nuclei stained with Hoechst 33342. f Fluorescent intensity histogram of LAN5 cells incubated with different doses of synaptosomes labeled with CTX-FITC (Synap CTX-FITC 5-10 and $20 \mu \mathrm{ll}$ ). g Representative fluorescence images of Synap CTX-FITC and LAN5 cells interaction. Nuclei were stained with Hoechst 33342. $\mathbf{h}$ Schematic representation of the localization of Rat synaptophysin (Rat SyP) (red) and Human synaptophysin (Human SyP) (yellow) before and after administration of synaptosomes in LAN5 cell. i Western blot analysis of proteins extracted from LAN5 cells untreated (Control) or treated with different doses of synaptosomes (5-10-20 $\mu$ l) (Lan5 + synap), and from synaptosomes incubated with anti-Synaptophysin (SyP). j Relative quantification of Rat synaptophysin (Rat SyP) immunoreactive band ( $36 \mathrm{kDa}$ ). The uniformity of gel loading was confirmed by using $\beta$-actin as a standard. ${ }^{*} P<0.05$, **P $<0.02$ vs Control. Scale bar $20 \mu \mathrm{m}$. Synap 5-10 and $20 \mu$; correspond to concentration of $2.5 \times 10^{7} ; 5.1 \times 10^{7} ; 10.2 \times 10^{7}$ particles/100 $\mu$ respectively)
} 


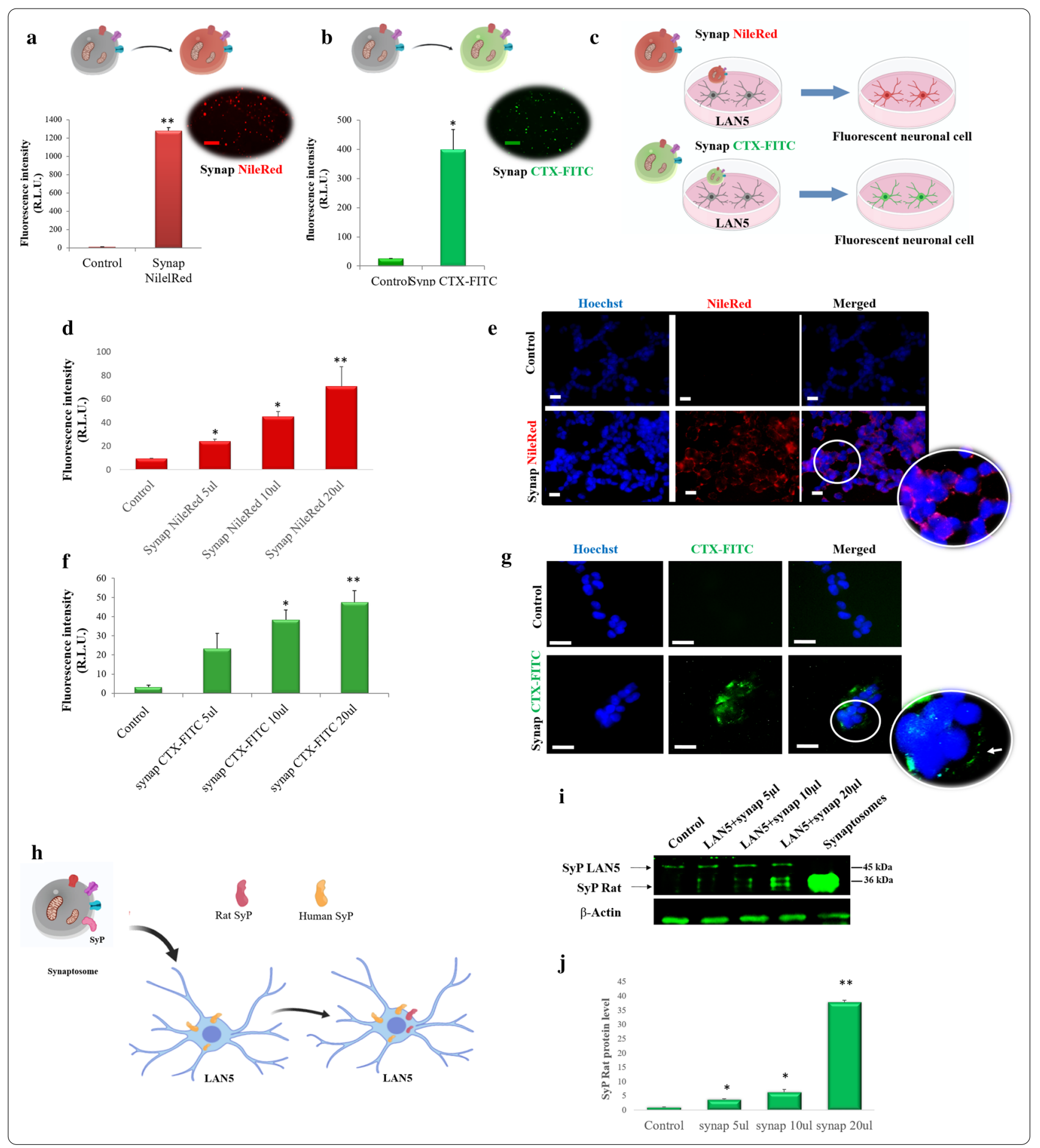

(Fig. 5f, g), showing that despite the temperature variations, their functionality was preserved. Moreover, the synaptosomes' long-term storage up to 12 months did not influence the valuated synaptosomal parameters (data not shown). Thus, from the next experiments, we used freeze/thawed synaptosomes.

\section{Synaptosomes as mitochondrial delivery systems}

We explored the possibility of using synaptosomes to transfer functional mitochondria in cells. There are various techniques for mitochondrial transplantation, but the opportunity to use synaptosomes as a delivery system has not been explored yet. 


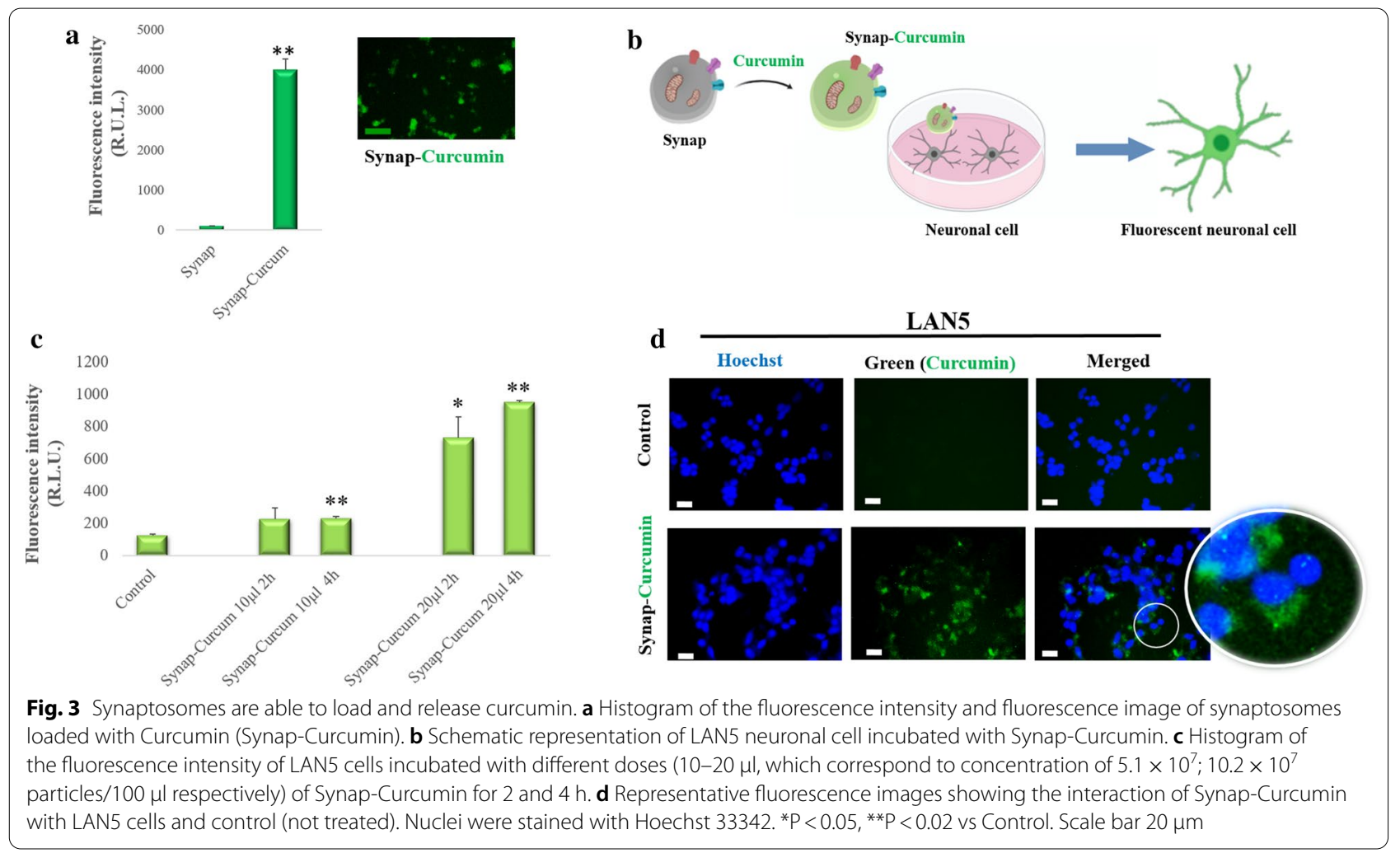

Synaptosomes containing JC1 stained mitochondria (Synap-JC1) were administrated to LAN5 cells and incubated for two different time intervals (Fig. 6a). After two hours of incubation, a light punctate red fluorescence was detected by fluorescence microscopy on LAN5 membranes, whereas after $4 \mathrm{~h}$, an intense red fluorescence was observed in LAN5 cytoplasm, suggesting that cellular uptake of the synaptosomal-mitochondria occurred (Fig. 6b). Dynamic imaging simulation was performed to detect uptake and trafficking of SynapJC-1 fully. As shown in Fig. 6c, after 2 h, some synaptosomes were approaching the cells while others were interacting with the cellular membrane. After $4 \mathrm{~h}$, Synapt-JC-1 were absorbed by the cells. The increase in mitochondrial uptake overtime was confirmed by fluorescence measurements that showed a significant fluorescence intensity inside the cells after $4 \mathrm{~h}$ (Fig. 6d). The efficiency of mitochondrial cell delivery, defined as the percentage of live cells receiving mitochondria, was around $40 \%$ after $4 \mathrm{~h}$.

As a further check, the presence of specific mitochondrial proteins such as TOM40, Cytochrome c and Hexokinase II was searched in recipient cells after incubation with their specific antibodies. Figure $6 \mathrm{e}$ and $\mathrm{F}$ show that all three proteins are much more considerable than in control. Finally, to confirm the occurrence of mitochondrial transfer, PCR analysis was performed. As expected, the amount of Rat mtDNA (mitochondrial DNA) significantly increased in LAN5 cells proportionally to the number of synaptosomes administrated, whereas Human mtDNA and nDNA (nuclear DNA) did not change (Fig. 6g). Thus, synaptosomes can be considered a valid delivery system for transplanting healthy mitochondria.

\section{Restore of mitochondrial homeostasis by mitochondrial transfer}

We investigated the possibility of replacing damaged with healthy mitochondria within a cell by using synaptosomes as vehicles. To this purpose, we treated LAN5 cells with CCCP or Rotenone, two compounds that induce mitochondrial dysfunction and disruption. After the treatment, red fluorescence emitted by JC1 vital mitochondria was found to decrease with respect to the control, highlighting that mitochondrial function had been inhibited (Fig. 7a, c). Then, synaptosomes were administered in a different dose and re-observed by fluorescence measurements. A dose-dependent increased red fluorescence was observed, indicating that the healthy mitochondria transported by synaptosomes had restored the damaged mitochondrial activity (Fig. 7a, c). The recovery of mitochondrial activity in damaged LAN5 cells after 


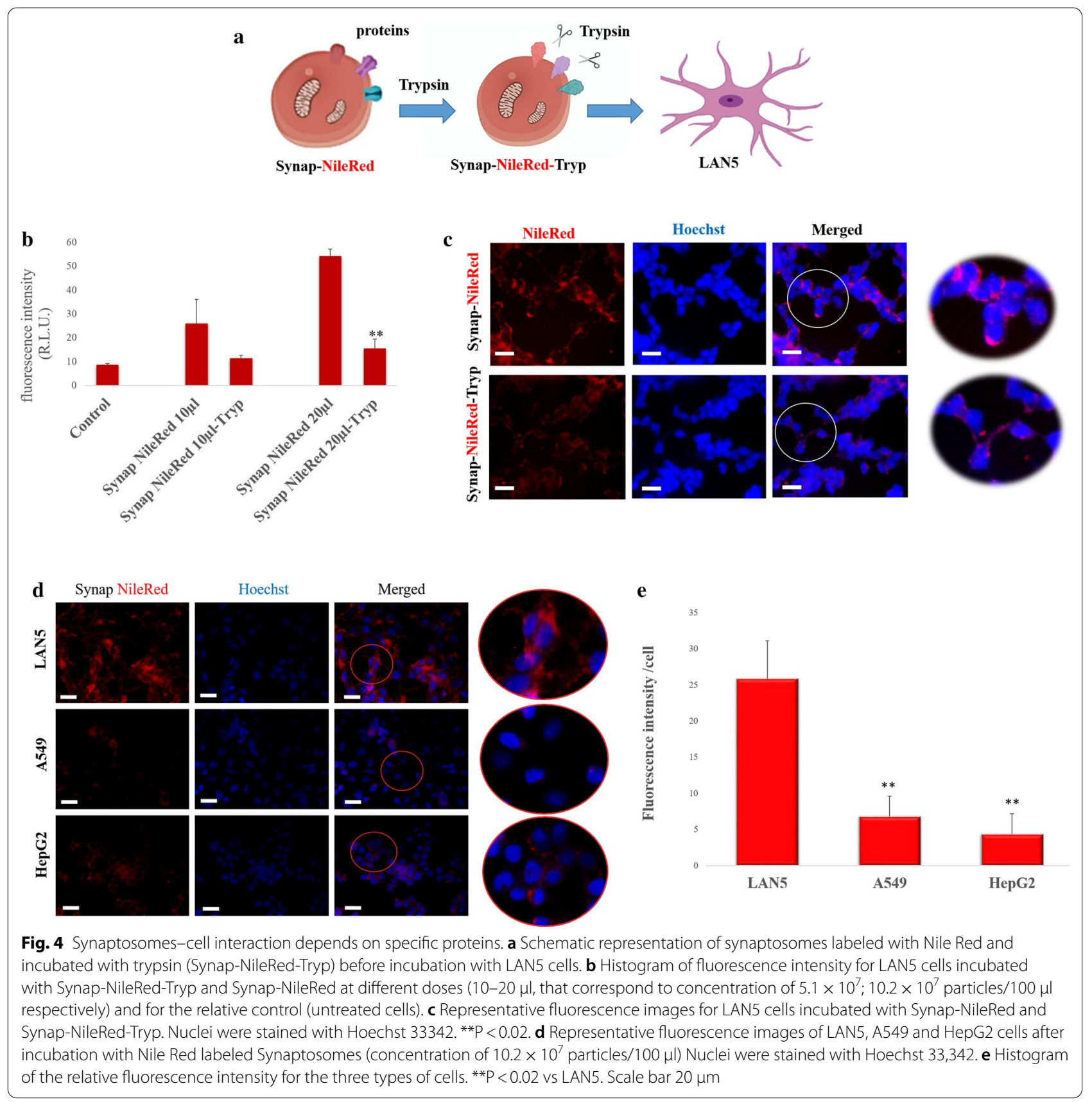

synaptosomes treatment was also confirmed by microscopy fluorescence inspection (Fig. 7b, d).

\section{Discussion}

Mitochondrial dysfunction constitutes the base of pathological events, including neurological diseases [2]. Decreasing of ATP production and endogenous antioxidants, increasing of ROS generation, and alteration of membrane potential are the main characteristics of damaged mitochondria. Although considerable much work has been done to discover therapeutic drugs targeted to mitochondrial dysfunction, so far, no clinical treatment is still available. Mitochondrial transplantation is an innovative technique based on the possibility of replacing damaged mitochondria with healthy exogenous mitochondria [16-18]. The most challenging step in the method is the mitochondria delivery since during the transfer, mitochondria must overcome the transition from an intracellular to an extracellular environment and 


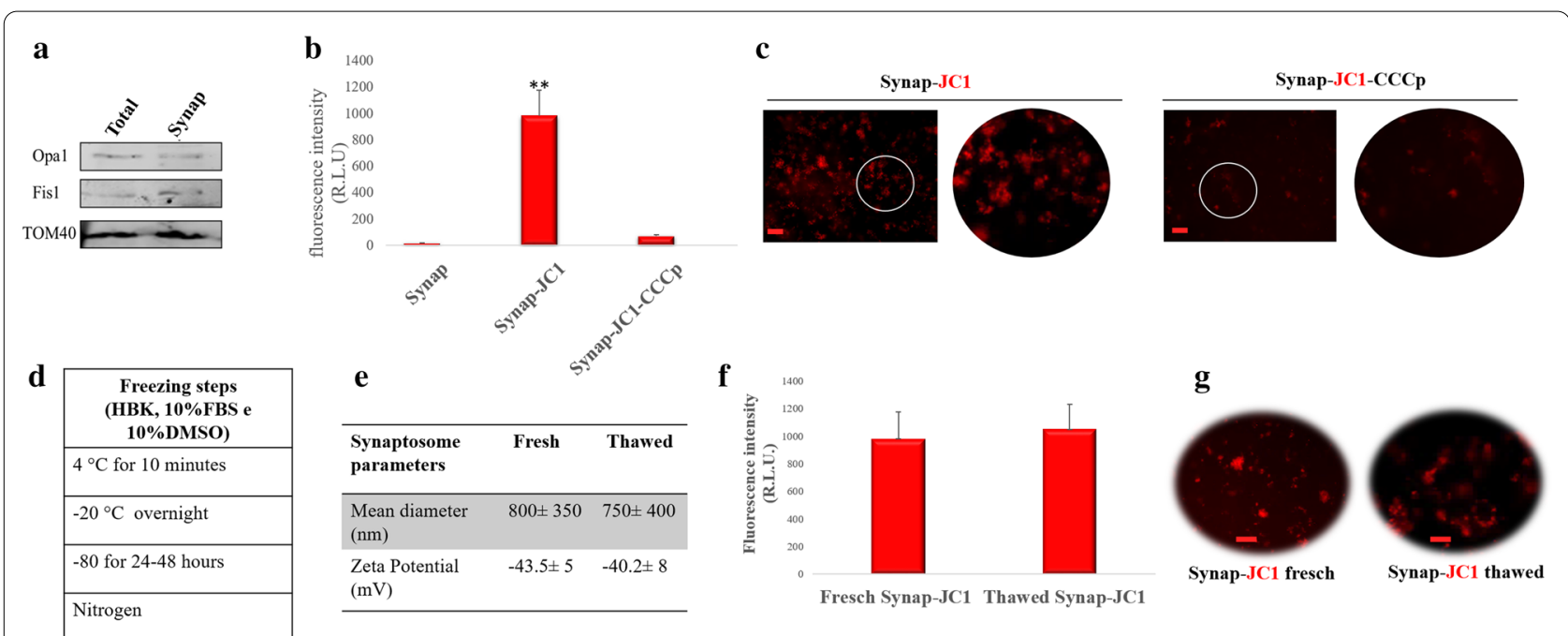

Fig. 5 Synaptosomes contain vital mitochondria. a Western blotting analysis of proteins extracted from total homogenate (Total) and synaptosomal fraction (Synapt) incubated with antibodies against the mitochondrial proteins Opa1, Fis 1 and TOM40. b Red fluorescence intensity for synaptosomes incubated with or without (Synap) JC1 and for synaptosomes treated with CCCp and incubated with JC-1 (Synap-JC1-CCCP) (positive control). c Representative JC1 fluorescence images of synaptosomes incubated with or without (Synap-JC1) CCCp. Cryopreservation of Synaptosomes $\mathbf{d}$ Schematic representation of the synaptosomes freezing procedure. e Table of the values of mean diameter and zeta potential of fresh and thawed synaptosomes. $\mathbf{f}$ Red fluorescence intensity of fresh (fresh Synap-JC1) and thawed (thawed Synap-JC1) synaptosomes incubated with JC-1. g Representative JC1 red fluorescence images of fresh and thawed synaptosomes incubated with JC-1. **P $<0.02$ vs Control. Scale bar $20 \mu \mathrm{m}$

overcome cell membrane and barriers. Currently applied methodologies for mitochondrial transfer employ naked mitochondria and up to now, no delivery system has been reported. The use of naked mitochondria presents a limit in terms of delivery efficiency due to the possible occurrence of mitochondrial damage and functional alteration during the isolation and transfer processes associated with no specific cellular target $[28,29]$. The possibility to encapsulate mitochondria within liposomes has been explored, but some difficulties have been found in organelle packaging [19]. To overcome this problem, it has been recently proposed to use a cell-penetrating peptide (Pep-1) conjugated with mitochondria, and improved uptake by the recipient cells and mitochondrial rescue function were observed [20]. Here, we take evidence that synaptosomes can be a neuronal delivery system of naturally encapsulated mitochondria.

Preparation of Synaptosomes was validated by the presence of Synaptophysin and PSD95 and, consistently with other reports, by intact particles ranging between $0.5-1.5 \mu \mathrm{m}$ [30]. Further, the high value of the $\zeta$ potential and the polydispersity index signified that synaptosomes have good stability, do not tend to flocculate or aggregate and maintain their functional integrity, suggesting that they could be suitable vehicles for the delivery of their cargo, including mitochondria.
An effective delivery system requires an efficient uptake and release of the encapsulated molecules into cells. Nile red or CTX-FITC labelled synaptosomes were internalized into LAN5 recipient cells, as demonstrated by the fluorescence increase and rat synaptophysin presence. Cellular uptake suggests that synaptosomes can be fused with the plasma membrane through a mechanism that appears mediated by specific proteins. After trypsin treatment, indeed, synaptosomes lost their fusion ability. Furthermore, the presence of proteins involved in membrane fusion machineries such as SNARE and SNAP-25 has been demonstrated by the synaptosomal proteomic approach [31]. The specificity of uptake by neuron cells suggests that synaptosomes could contain proteins that act as specific and natural directing agents for the brain. Similar behaviour has been noticed in exosomes released from stimulated cortical neurons that interact selectively with neurons [32]. In addition, the release ability was demonstrated by the presence in LAN5 cellular body of curcumin previously loaded on synaptosomes. Thus, the physical-chemical characteristics, the ability of cell uptake, the cargo release and the specific cell targeting make synaptosomes a natural neuronal delivery system.

The synaptosomes contain mitochondria as demonstrated by the presence of specific mitochondrial proteins such as Opa1, Fis1 and TOM40, and their vitality was confirmed by maintaining of the membrane potential. 


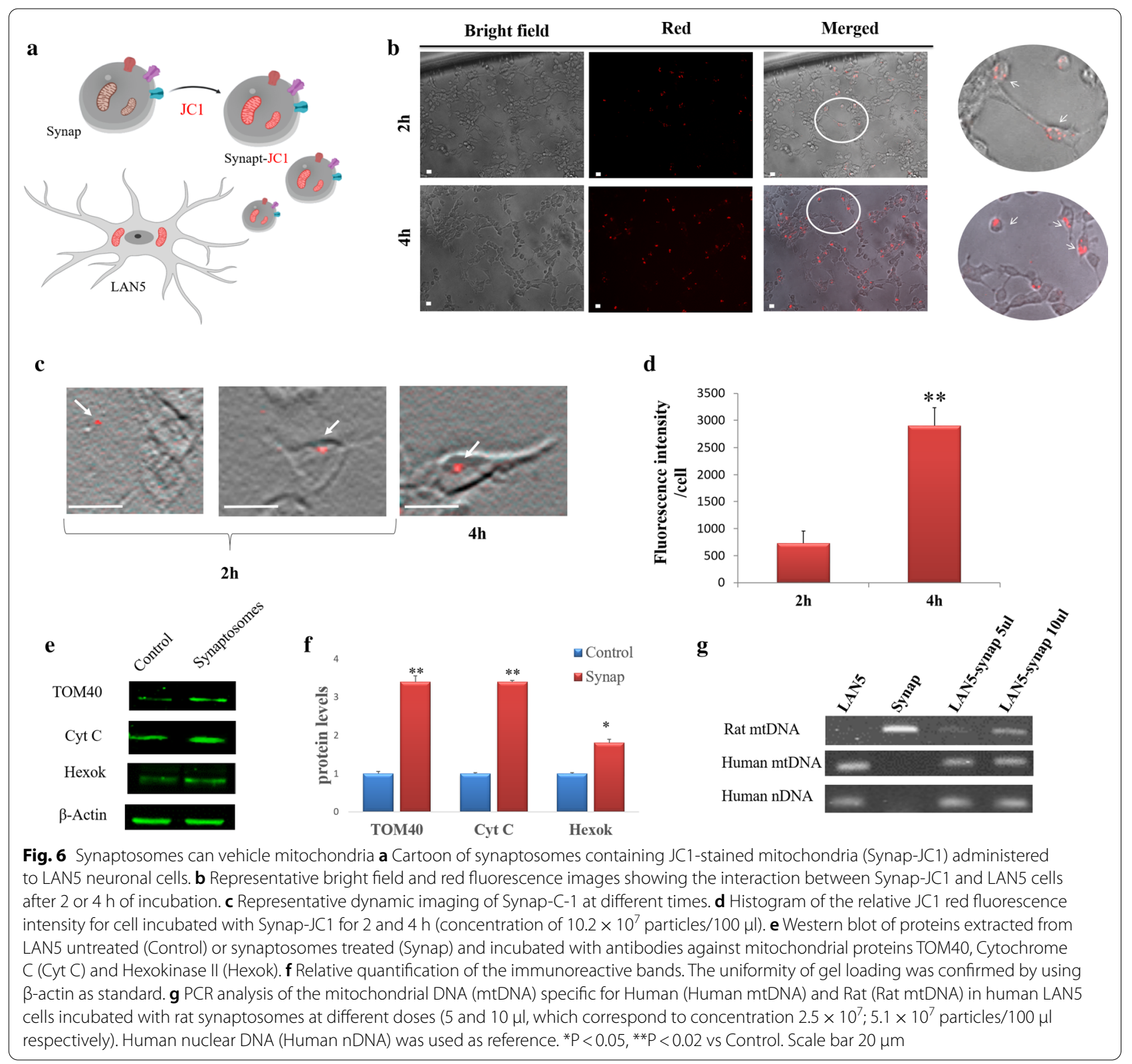

Furthermore, vital JC1-labeled mitochondria after internalization were released by synaptosomes into the cytosol of neuronal cells, as demonstrated by an increase of fluorescence. Further, an increase of TOM 40, cytochrome C, Hexokinase II proteins and the presence of mitochondrial rat DNA, suggests that synaptosomes could be a vehicle for vital mitochondrial transfer. In addition, the supplement of healthy mitochondria into cells treated with rotenone or CCCp damaged mitochondria was beneficial to restore the mitochondrial function. Hence, synaptosomes can be both the source and the delivery system of mitochondria.
In physiological conditions, mitochondria can be transferred from a donor cell to an injured recipient cell by different contact modes, including tunnelling nanotubes, extracellular vesicles, cell-cell fusion, GAP junctions [33-35]. On the basis of these knowledge, McCully and colleagues employed mitochondrial transplantation as a therapeutic approach to treat ischemia both in animal models and in paediatric patients [18, 36]. Mitochondrial transplantation is reported as a "magical" cure [28], since healthy organelles, harvested by unaffected tissue, after injection in the ischemic hearth move to the injured cells, 


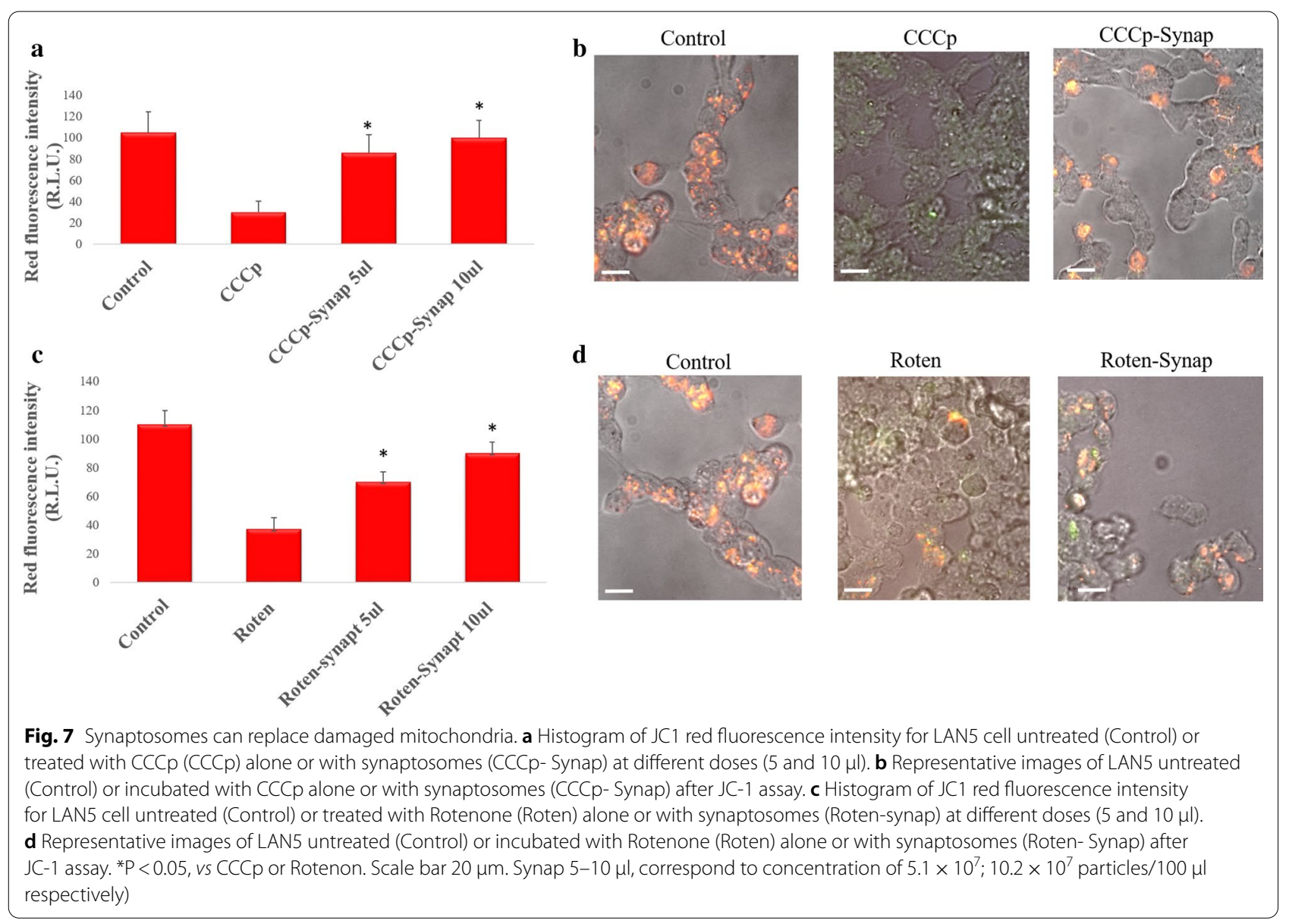

rescue ATP energy production and improve the contractile function in $10 \mathrm{~min}$ [36]. However, this approach, as stated before, present some problems regarding mitochondrial survival during the transfer. Only a small percentage $(10 \%)$ of the injected mitochondria reaches the target cells and exerts a therapeutic effect [17]. Although mitochondrial supplementation has been mainly utilized for cardiac injuries, this approach has also been applied for the treatment of NDs and other injuries of the nervous system. $[19,29,37]$. In the brain, the use of synaptosomes could improve mitochondrial delivery by protecting the organelle during the transfer, facilitating their specific cellular uptake and reducing stress in the recipient cells. Further, the time of mitochondria transfer could be reduced. The possibility to use synaptosomes as a delivery system for mitochondria agrees with the suggested possibility to encapsulate isolated mitochondria in biomaterials for improving their delivery to the brain and subsequent uptake by cells [37]. In addition, to load antioxidant molecules, such as curcumin, within synaptosomes could be an additional strategy to protect mitochondria by stress occurring during their transfer and/or into the beneficiary cells.

McCully and colleagues indicated that for successful mitochondrial transplantation, vital mitochondria once isolated must be immediately used since, as for their experience, frozen mitochondria do not play their cardioprotection role [36].

Our findings demonstrate that synaptosomes can be cryopreserved for a long time. Indeed, they maintain after thawing their physical-chemical properties and deliver mitochondria vital and physiologically active. Cryopreservation can be a valid strategy in experimental procedures for reducing the number of sacrificed animals and allowing them to do experiments whenever required.

Nowadays, the brain donation program is one of the most valued contribution to scientific research. Differently from other organ donations, the brain is not used to be transplanted, but half tissue is used for clinic analyses and half is kept, for eventual scientific studies, in a brain bank. Thus, we cannot exclude that in the future, synaptosomes could be extracted from the brain of donors, kept in a synaptosomal-bank and used as a source of 
mitochondria when necessary for transplantation in mitochondria-damaged neuronal cells (Fig. 8).

This procedure could permit to have an always-available source of functional mitochondria ready to be transplanted, overcoming the necessity to isolate fresh mitochondria and reducing the time before transplantation. In medical practice, indeed, it is necessary to obtain functional mitochondria in a short time because protracting surgeries could be counterproductive. However, for clinical application, the criteria of Good Manufacturing Practice (GMP) have to be established. Quality control of size, number, viability and function of both synaptosomes and organelles must be validated. Furthermore, delivery protocols require to be developed for establishing the number of mitochondria-delivered synaptosomes and the administration route. For cardiac injuries, isolated mitochondria have been transplanted by systemic or in situ injection and both the methods have desirable and undesirable effects [29]. A high number of mitochondria can be transplanted by systemic injection, but they might also be spread in no-injured tissues [31]. By in situ injection, all the isolated mitochondria can be delivered to the target tissue, but side effects due to accumulation of the organelles could occur [38]. Further, the injection could not be repeated if necessary during the surgery. In situ transplantation of mitochondria into CNS has been performed in preclinical studies, but its application in clinic results remains arduous [19]. Recently, the possibility to transplant isolated mitochondria in the damaged brain through the cerebrospinal fluid (CSF) has been explored [39]. Thus, the intraspinal injection could be a new route for transferring mitochondria to the brain and synaptosomes could facilitate the delivery.

\section{Conclusion}

Synaptosomes are not only a source of mitochondria but also a natural delivery system that could improve their neuronal transfer and cellular uptake. Mitochondrial transplantation is a smart strategy to replace or supplement damaged mitochondria. Overall, synaptosome-mediated mitochondrial transplantation could be applicable for the treatment of many brain diseases in which traditional therapies have been unsuccessful.

\section{Methods}

Synaptosomes isolation from fresh brain tissue

Synaptosomes were isolated by a modification of the method by Franklin et al., (2016) [40]. Briefly, Wistar rats were purchased from Charles River Laboratories (Calco-Lecco, Italy). Explanted rat brains were donated from Palermo University (Italy) in accordance with the authorization number 69636.N.JCO approved by Italian Ministry of Health (Rome, Italy). The cortex (60 mg) was quickly removed and homogenized in $180 \mu \mathrm{L}$ of $0.32 \mathrm{M}$ sucrose with $10 \%$ protease (Amersham Biosciences, Milan, Italy) and phosphatase cocktail inhibitors (cocktail II and III; Sigma-Aldrich, Milan, Italy) with a Dounce on ice. An aliquot $(10 \mu \mathrm{l})$ was immediately flash-freeze in liquid nitrogen and saved as homogenate.

The homogenate $(170 \mu \mathrm{l})$ was mixed with $720 \mu \mathrm{L}$ of $2 \mathrm{M}$ sucrose and $300 \mu \mathrm{L}$ of $0.1 \mathrm{mM} \mathrm{CaCl} 2$, transferred to $5 \mathrm{ml}$ ultracentrifuge tube and ultracentrifuged at 127,000 RCF for $3 \mathrm{~h}$ at $4{ }^{\circ} \mathrm{C}$ by using TLA110 rotor (Beckman Coulter, Brea, CA). Successively, the myelin layer floating on the top was discarded, and the synaptosomal band at the sucrose layers interface was collected (Fig. 1b). Then, the synaptosomal band was transferred into an

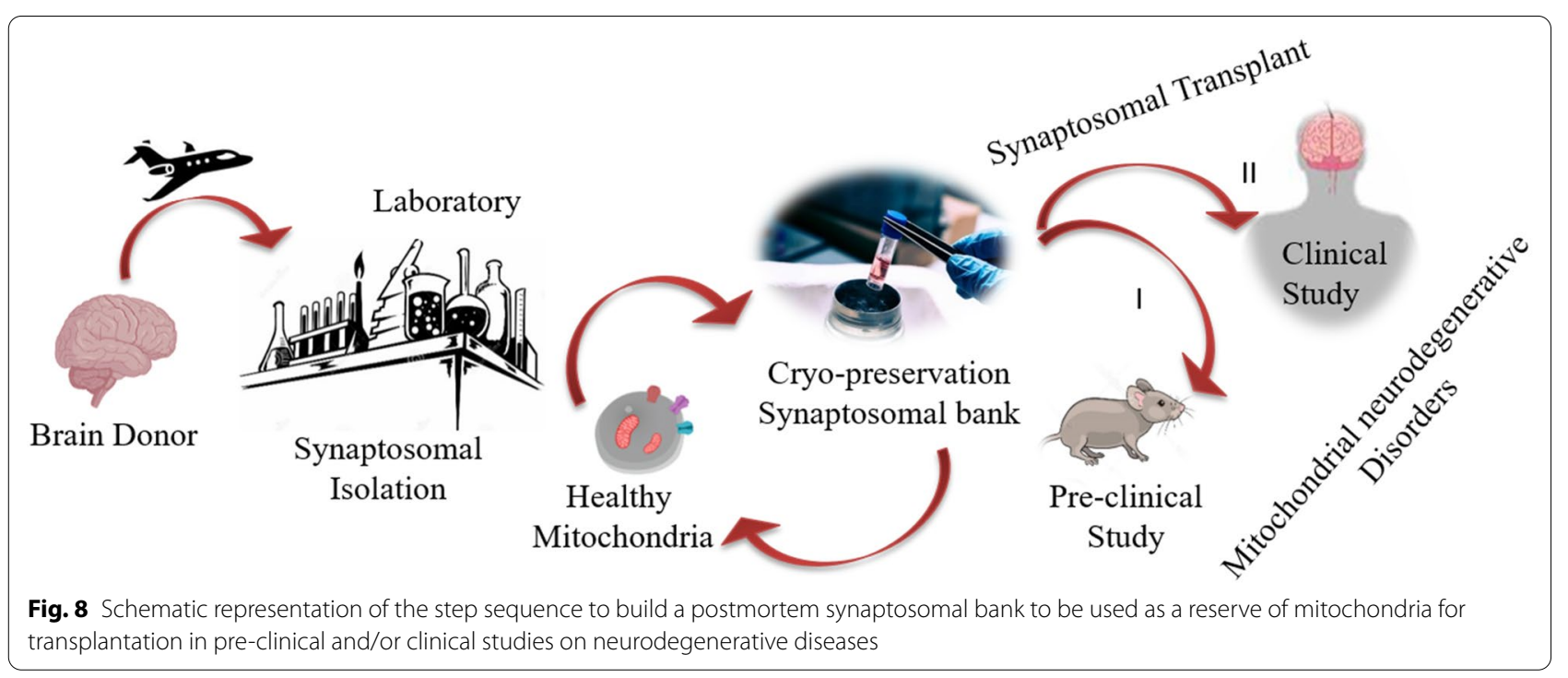


ultracentrifuge tube and centrifuged at 18,200 RCF for 30 min at $4{ }^{\circ} \mathrm{C}$ in TLA110 rotor (Beckman Coulter, Brea, CA). The supernatant was discarded and the pellet, containing the synaptosomes, was resuspended in $5 \mathrm{ml}$ of HBK buffer (HEPES-buffered Krebs-like) (143 mM NaCl, $4.7 \mathrm{mM} \mathrm{KCl}, 1.3 \mathrm{mM} \mathrm{MgSO}, 1.2 \mathrm{mM} \mathrm{CaCl} 2,20 \mathrm{mM}$ HEPES, $0.1 \mathrm{mM} \mathrm{NaH}_{2} \mathrm{PO}_{4}$ e $10 \mathrm{mM}$ D-glucose a pH 7.4) to be analyzed.

For cryopreservation, the synaptosomal pellet was suspended in $5 \mathrm{ml}$ HBK buffer containing 10\% Fetal Bovine Serum (FBS) (Gibco-Invitrogen, Milan, Italy), 10\% DMSO, split into 5 aliquots $(1 \mathrm{ml})$ and cryopreserved by performing a sequence of controlled freezing steps consisting in $10 \mathrm{~min}$ at $4{ }^{\circ} \mathrm{C}$, overnight at $-20{ }^{\circ} \mathrm{C}, 24-48 \mathrm{~h}$ at $-80{ }^{\circ} \mathrm{C}$. Finally, the aliquots were stored in liquid nitrogen.

\section{Zeta potential, concentration and polydispersity index}

Fresh or thawed Synaptosomal aliquots were resuspended in $2.5 \mathrm{ml}$ HBK and diluted (1:100) in PBS 1X. The zeta potential, concentration (particles/ml) and polydispersity index were measured using the instrument ZetaView $^{\circledR}$ BASIC NTA-Nanoparticle Tracking Video Microscope PMX-120.

\section{Quasi-elastic laser light scattering (QELS)}

Fresh or thawed Synaptosomal aliquots were resuspended in $2.5 \mathrm{ml}$ of HBK $\left(5.1 \times 10^{9} \pm 0.7 \times 10^{9}\right.$ particles/ $\mathrm{ml}$ ) and QELS experiments were carried out at T $25{ }^{\circ} \mathrm{C}$ after synaptosomes dilution (1:10) in HBK at $\mathrm{pH}$ 7.4. The cuvette was placed in the thermostatically controlled cell compartment of a Brookhaven Instrument BI200-SM goniometer equipped with a $15 \mathrm{~mW}$ He-Neon Spectra Physics laser tuned at $\lambda 632.8 \mathrm{~nm}$. The temperature was controlled within $0.05{ }^{\circ} \mathrm{C}$ by a circulating bath. Scattered light intensity at $90^{\circ}, \mathrm{I}^{\circ} 0^{\circ}(\mathrm{t})$, and its time autocorrelation function, $g 2(t)$, were measured by using a Brookhaven BI-9000 correlator. Autocorrelation functions g2(t) were analyzed using a smoothing constrained regularization method CONTIN [41] to obtain the intensity weighted diameter distribution of synaptosomes.

\section{Atomic Force Microscopy (AFM)}

Fresh or thawed synaptosomal aliquots were resuspended in $2.5 \mathrm{ml} \mathrm{HBK}\left(5.1 \times 10^{9}\right.$ particles $\left./ \mathrm{ml}\right)$ and diluted (1:1000). $50 \mu \mathrm{l}$ of the synaptosome suspension were deposited on freshly cleaved mica, washed after few minutes and dried under a mild vacuum. Tapping mode AFM images were acquired in the air using a multimode scanning probe microscope driven by a Nanoscope V controller (Digital Instruments, Bruker).
Single beam uncoated silicon cantilevers (type SPM Probe Mikromasch) were used. The drive frequency was between 260 and $325 \mathrm{kHz}$; the scan rate was $0.25-0.7 \mathrm{~Hz}$.

\section{Cell cultures and treatments}

LAN5 neuroblastoma, HepG2 human liver cancer and A549 adenocarcinomic human alveolar basal epithelial cell lines, were cultured with RPMI 1640 medium (Celbio srl, Milan, Italy) supplemented with 10\% FBS (Gibco-Invitrogen, Milan, Italy), $2 \mathrm{mM}$ glutamine and $1 \%$ penicillin, $1 \%$ streptomycin $(50 \mathrm{mg} / \mathrm{ml})$ (Sigma). The cells were treated with synaptosomes $\left(5.1 \times 10^{9}\right.$ particles $\left./ \mathrm{ml}\right)$, at different dilutions $5-10-20 \mu \mathrm{l}$ in $100 \mu \mathrm{l}$ of cell medium for 2,4 or $24 \mathrm{~h}$ (corresponds to concentration of $2.5 \times 10^{7}$; $5.1 \times 10^{7} ; 10.2 \times 10^{7}$ particles $/ 100 \mu \mathrm{l}$ respectively).

In transplantation experiments, cells were pre-treated with $40 \mu \mathrm{M}$ rotenone for $1 \mathrm{~h}$ and $50 \mu \mathrm{M}$ of Carbonyl cyanide 3- chlorophenylhydrazone (CCCp) for $5 \mathrm{~min}$ at $37{ }^{\circ} \mathrm{C}$. After washing, cells were incubated without or with synaptosomes at different dilutions $(5-10 \mu \mathrm{l}$ in $100 \mathrm{ul}$ of the medium) for $24 \mathrm{~h}$ at $37^{\circ} \mathrm{C}$. When indicated, synaptosomes were treated with $1 \mathrm{X}$ trypsin (Sigma) or with $50 \mathrm{mM}$ CCCp for $5 \mathrm{~min}$.

\section{Synaptosomes labeling with membrane fluorescence dyes}

Fresh or thawed synaptosomal aliquots were resuspended in $2.5 \mathrm{ml} \mathrm{HBK}$. $500 \mu \mathrm{l}$ of the synaptosome solution $\left(5.1 \times 10^{9}\right.$ particles $\left./ \mathrm{ml}\right)$ were stained by the membrane dye Nile Red or fluorescein-tagged cholera toxin (CTXFITC). Nile Red is used to stain lipids since it is highly fluorescent in a non-polar environment (excitation/emission 490/590). CTx-FITC stains lipid rafts (excitation/ emission maxima 490/535). For staining, synaptosomes were incubated in HBK buffer with Nile Red $(5 \mu \mathrm{g} / \mathrm{ml})$ for $15 \mathrm{~min}$ and with CTX-FITC $(10 \mu \mathrm{g} / \mathrm{ml})$ for $30 \mathrm{~min}$ at $37{ }^{\circ} \mathrm{C}$ in the dark. After incubation, synaptosomes were centrifuged at 10,000 RCF for $10 \mathrm{~min}$ and then washed two times with HBK to remove the dye excess. Fluorescence emission of synaptosomes marked with Nile Red or CTx-FITC was measured by fluorimeter (Glomax) and fluorescence microscopy (Zeiss).

\section{Cellular uptake of Synaptosomes}

For uptake studies, LAN5, HepG2, and A549 cells were plated at the concentration of $3 \times 10^{5} \mathrm{cell} / \mathrm{ml}$ in 96 -well plate. The cells were incubated with $20 \mu \mathrm{l}$ of synaptosomes $\left(10.2 \times 10^{7}\right.$ particles/100 $\left.\mu \mathrm{l}\right)$, labeled with Nile Red for $4 \mathrm{~h}$. After washing with PBS, the incorporated fluorescence was measured by a fluorescence microscope (Axio Scope 2 microscope; Zeiss) or fluorimeter (Glomax). The 
levels of fluorescence for the cell was analyzed by Image J software to compare the fluorescence intensity between the different cell lines.

\section{Synaptosomes release assay}

To test the ability of synaptosomes to release molecules into cells, we used curcumin, a natural fluorescent compound. Fresh or thawed synaptosomal aliquots were resuspended in $2.5 \mathrm{ml}$ of $\mathrm{HBK}$ and curcumin loading was performed by incubating $500 \mu \mathrm{l}$ of synaptosomes $\left(5.1 \times 10^{9}\right.$ particles $\left./ \mathrm{ml}\right)$ with curcumin $(5 \mu \mathrm{M})$ overnight at room temperature. Then, the excess of curcumin in the sample was removed by centrifugation at 10,000 RCF for 10 min and two washes with HBK. The amount of curcumin incorporated in synaptosomes was measured by using a fluorimeter (Glomax) and fluorescence microscopy (Zeiss). LAN5 cells were plated at the concentration of $3 \times 10^{5} \mathrm{cell} / \mathrm{ml}$ in a 96-well plate and incubated with 10 or $20 \mu \mathrm{l}$ curcumin-loaded synaptosomes $\left(5.1 \times 10^{7}\right.$; $10.2 \times 10^{7}$ particles $/ 100 \mu \mathrm{l}$ ) for 2 and $4 \mathrm{~h}$. After treatment, cells were washed with PBS, and the emitted fluorescence was evaluated by fluorescence microscope (Axio Scope 2 microscope; Zeiss) or fluorimeter (Glomax) Excitation/ emission maxima $\sim 490 / 535$.

\section{Analysis of mitochondrial activity in synaptosomes}

Membrane potential of synaptosomal mitochondria was measured using MitoProbe JC-1 assay kit (Thermo Fisher Scientific-US). JC-1 (5,50,6,60-tetrachloro1,10,3,30-tetraethylbenzimidazolyl-carbocyanine iodide) is a dye that enters into mitochondria and changes colour from green to red as the membrane potential increases. Fresh or thawed synaptosomal aliquots were resuspended in $2.5 \mathrm{ml}$ of $\mathrm{HBK}$ and $100 \mu \mathrm{l}$ were plated in a 96-well plate. After the addition of JC-1 $(2 \mu \mathrm{M})$, the sample was incubated for $30 \mathrm{~min}$ at $37^{\circ} \mathrm{C}$. CCCp $(50 \mu \mathrm{M})$, a mitochondrial membrane potential disrupter, was used as control. The excitation length for JC-1 is $490 \mathrm{~nm}$, and red and green emission lengths are 590 and $529 \mathrm{~nm}$, respectively.

\section{Synaptosomal mitochondria delivery}

Fresh or thawed synaptosomal aliquots were resuspended in $2.5 \mathrm{ml}$ of HBK and $500 \mu \mathrm{l}\left(5.1 \times 10^{9}\right.$ particles $\left./ \mathrm{ml}\right)$ were incubated with $2 \mu \mathrm{M} \mathrm{JC}-1$ (Thermo Fisher Scientific-US) for $30 \mathrm{~min}$ at $37^{\circ} \mathrm{C}$ in the dark, and then washed two times in PBS to remove the dye excess. LAN5 cells were plated at the concentrations of $3 \times 10^{5} \mathrm{cell} / \mathrm{ml}$ in a 96 -well plate and incubated with synaptosomes containing JC-1 marked mitochondria for 2 and $4 \mathrm{~h}$. After the treatment, cells were washed with PBS, and the fluorescence was evaluated by fluorescence microscope (Axio Scope 2 microscope; Zeiss). The excitation and emission lengths were 490 and $590 \mathrm{~nm}$, respectively. The levels of fluorescence for the cell was analyzed by Image J software.

\section{Total protein extraction and Western blotting}

Total proteins were extracted by dissolving cells and synaptosomes in the solubilizing buffer $(50 \mathrm{mM}$ Tris$\mathrm{HCl}$ pH 7.4, $150 \mathrm{mM} \mathrm{NaCl}, 0.5 \%$ Triton X-100, $2 \mathrm{mM}$ phenylmethylsulphonyl fluoride PMSF,1mMDTT, $0.1 \%$ SDS) with protease inhibitor (Amersham Biosciences, Milan, Italy) and phosphatase inhibitor (cocktail II and III; Sigma Aldrich, Milan, Italy). Protein samples $(30 \mu \mathrm{g})$ were submitted to $10 \%$ SDS PAGE and transferred onto nitrocellulose filters. The Western blot was incubated with anti-TOM40 (1:1000; Cell Signaling, Boston, USA), anti-Cytochrome C (1:1000; Cell Signaling, Boston, USA), anti-OPA1 (1:1000; Cell Signaling, Boston, USA), anti-FIS1(1:1000; Cell Signaling, Boston, USA), antisynaptophysin (1:2000; Cell Signaling, Boston, USA), PSD95(1:1000; Cell Signaling, Boston, USA), anti- $\beta$ Actin (1:1000; SIGMA) antibodies. Primary antibody was detected by the Odyssey scanner (L-Licor) and using secondary antibody labeled with IR 790, (1:10,000; Life Technology) according to the manufacturer's instructions. Band intensities were analyzed with ImageJ and expression was adjusted to $\beta$ Actin expression. The protein levels were expressed as intensity relative to control.

\section{Statistical analysis}

All experiments were repeated three times, and in each experiment, the samples were taken in triplicate. The results are presented as mean \pm SD. Statistical evaluation was conducted by ANOVA, for analysis of significance. Results with a $P$ value $p \leq 0.05$ were considered statistically significant, ${ }^{*} \mathrm{P} \leq 0.05,{ }^{* *} \mathrm{P} \leq 0.01$.

\section{Supplementary Information}

The online version contains supplementary material available at https://doi. org/10.1186/s12951-020-00748-6.

Additional file 1: Figure S1. A) Morphological analysis of LAN5 cells incubated with different doses (5-10 and $20 \mu$, which correspond to concentration of $2.5 \times 107 ; 5.1 \times 107 ; 10.2 \times 107$ particles/100 $\mu$ l respectively) of synaptosomes (Synap). B) Nuclear staining by fluorescence probe Hoechst 3341 of LAN5 cells incubated with different doses (5-10 and 20 $\mu \mathrm{l})$ of synaptosomes (Synap).

\section{Acknowledgements}

The authors wish to thank Mr. Luca Caruana for its helpful technical support and Dr. Marco Contardi for the critical revision of the manuscript.

\section{Authors' contributions}

PP design and conduction of the research, analysis and interpretation of the data and writing of the initial draft of the manuscript; GP and CCB, conduction of the research and analysis of the data, DN and G.G. conduction of the 
research, PLSB and DB analysis and interpretation of the data and revision of the manuscript, MDC interpretation of the data, drafting and critical revision of the manuscript. All authors read and approved the final manuscript.

\section{Funding}

This research received no external funding.

\section{Availability of data and materials}

The datasets used and/or analyzed during the current study are available from the corresponding author on reasonable request.

\section{Ethics approval and consent to participate}

Animal care was in accordance with institutional guideline and with the authorization number 69636.N.JCO approved by Italian Ministry of Health (Rome, Italy).

\section{Consent for publication}

No applicable.

\section{Competing interests}

The authors declare that they have no competing interests.

\section{Author details}

${ }^{1}$ Istituto per la Ricerca e I'Innovazione Biomedica (IRIB) CNR, via U. La Malfa 153, 90146 Palermo, Italy. ${ }^{2}$ Istituto di Biofisica (IBF) (sez. Palermo) CNR, via U. La Malfa, 153, 90146 Palermo, Italy. ${ }^{3}$ Dipartimento di Biomedicina, Neuroscienze, e Diagnostica Avanzata (BIND) (Sez. Anatomia Umana), Università di Palermo, via del Vespro 129, 90127 Palermo, Italy. ${ }^{4}$ Istituto Euro-Mediterraneo di Scienze e Tecnologie (IEMEST), via M. Miraglia, 20, 90139 Palermo, Italy.

Received: 2 October 2020 Accepted: 5 December 2020

Published online: 06 January 2021

\section{References}

1. Vanni S, Colini Baldeschi A, Zattoni M, Legname G. Brain aging: A lanusfaced player between health and neurodegeneration. J Neurosci Res. 2020;98:299-311.

2. Picone P, Nuzzo D, Caruana L, Scafidi V, Di Carlo M. Mitochondrial dysfunction: different routes to Alzheimer's disease therapy. Oxidative medicine and cellular longevity. 2014;2014:780179.

3. Zhou Z, Austin GL, Young L, Johnson LA, Sun R. Mitochondrial metabolism in major neurological diseases. Cells. 2018;7:229.

4. Elfawy HA, Das B. Crosstalk between mitochondrial dysfunction, oxidative stress, and age related neurodegenerative disease: etiologies and therapeutic strategies. Life Sci. 2019;218:165-84.

5. Danta CC, Piplani P. The discovery and development of new potential antioxidant agents for the treatment of neurodegenerative diseases. Expert Opin Drug Discov. 2014;9:1205-22.

6. Sun AY, Wang Q, Simonyi A, Sun GY. Resveratrol as a therapeutic agent for neurodegenerative diseases. Mol Neurobiol. 2010;41:375-83.

7. Levites Y, Weinreb O, Maor G, Youdim MB, Mandel S. Green tea polyphenol (-)-epigallocatechin-3-gallate prevents $\mathrm{N}$-methyl-4-phenyl1,2,3,6-tetrahydropyridine-induced dopaminergic neurodegeneration. J Neurochem. 2001;78:1073-82.

8. Picone P, Nuzzo D, Di Carlo M. Ferulic acid: a natural antioxidant against oxidative stress induced by oligomeric A-beta on sea urchin embryo. The Biological bulletin. 2013;224:18-28.

9. Sgarbossa A, Giacomazza D, di Carlo M. Ferulic acid: a hope for Alzheimer's disease therapy from plants. Nutrients. 2015;7:5764-82.

10. Picone P, Bondi ML, Montana G, Bruno A, Pitarresi G, Giammona G, Di Carlo M. Ferulic acid inhibits oxidative stress and cell death induced by Ab oligomers: improved delivery by solid lipid nanoparticles. Free Radical Res. 2009;43:1133-45.

11. Bondi ML, Montana G, Craparo EF, Picone P, Capuano G, Carlo MD Giammona G. Ferulic acid-loaded lipid nanostructures as drug delivery systems for Alzheimer's disease: preparation. Character Cytotox Stud Curr Nanosci. 2009;5:26-32.
12. Di Carlo M, Picone P, Carrotta R, Giacomazza D, San Biagio PL. Insulin promotes survival of amyloid-beta oligomers neuroblastoma damaged cells via caspase 9 inhibition and Hsp70 upregulation. J Biomed Biotechnol. 2010;2010:147835.

13. Picone P, Giacomazza D, Vetri V, Carrotta R, Militello V, San Biagio PL, Di Carlo M. Insulin-activated Akt rescues A $\beta$ oxidative stress-induced cell death by orchestrating molecular trafficking. Aging Cell. 2011;10:832-43.

14. Picone P, Ditta LA, Sabatino MA, Militello V, San Biagio PL, Di Giacinto ML, Cristaldi L, Nuzzo D, Dispenza C, Giacomazza D, Di Carlo M. Ionizing radiation-engineered nanogels as insulin nanocarriers for the development of a new strategy for the treatment of Alzheimer's disease. Biomaterials. 2016;80:179-94.

15. Mishra P, Chan DC. Metabolic regulation of mitochondrial dynamics. The Journal of cell biology. 2016;212:379-87.

16. Elliott $R$, Jiang $X$, Head J. Mitochondria organelle transplantation: a potential cellular biotherapy for cancer. J Surgery. 2015;9:1-3.

17. Emani SM, Piekarski BL, Harrild D, Del Nido PJ, McCully JD. Autologous mitochondrial transplantation for dysfunction after ischemia-reperfusion injury. J Thorac Cardiovasc Surg. 2017;154:286-9.

18. McCully JD, Levitsky S, Del Nido PJ, Cowan DB. Mitochondrial transplantation for therapeutic use. Clin Transl Med. 2016;5:6.

19. Gollihue JL, Patel SP, Rabchevsky AG. Mitochondrial transplantation strategies as potential therapeutics for central nervous system trauma. Neur Regener Res. 2018;13:194-7.

20. Chang JC, Hoel F, Liu KH, Wei YH, Cheng FC, Kuo SJ, Tronstad KJ, Liu CS. Peptide-mediated delivery of donor mitochondria improves mitochondrial function and cell viability in human cybrid cells with the MELAS A3243G mutation. Scie Rep. 2017;7:10710.

21. Whittaker VP, Michaelson IA, Kirkland RJ. The separation of synaptic vesicles from nerve-ending particles ('synaptosomes'). Biochem J. 1964;90:293-303.

22. Jhou JF, Tai HC. The study of postmortem human synaptosomes for understanding Alzheimer's disease and other neurological disorders: a review. Neurol Ther. 2017;6:57-68.

23. Zhang P, Liu G, Chen X. Nanobiotechnology: cell membrane-based delivery systems. Nano today. 2017;13:7-9.

24. Chu D, Dong X, Shi X, Zhang C, Wang Z. Neutrophil-based drug delivery systems. Adv Mater. 2018;30:e1706245.

25. Igbavboa U, Eckert GP, Malo TM, Studniski AE, Johnson LN, Yamamoto N, Kobayashi M, Fujita SC, Appel TR, Müller WE, Wood WG, Yanagisawa K. Murine synaptosomal lipid raft protein and lipid composition are altered by expression of human apoE 3 and 4 and by increasing age. J Neurol Sci. 2005;229-230:225-32.

26. Kadota T, Fujita M, Kadota K. Immunocytochemical localization of synaptophysin on the smooth-surfaced tubular membranes present in nerve terminal and preterminal areas in the rat cerebellar cortex. Arch Histol Cytol. 1991;54:519-25.

27. Bondi ML, Craparo EF, Picone P, Di Carlo M, Di Gesu R, Capuano G, Giammona G. Curcumin entrapped into lipid nanosystems inhibits neuroblastoma cancer cell growth and activates Hsp70 protein. Curr Nanosci. 2010;6:439-45.

28. Bertero E, Maack C, O'Rourke B. Mitochondrial transplantation in humans: "magical" cure or cause for concern? J Clin Investig. 2018;128:5191-4.

29. Roushandeh AM, Kuwahara Y, Roudkenar MH. Mitochondrial transplantation as a potential and novel master key for treatment of various incurable diseases. Cytotechnology. 2019;71:647-63.

30. Postupna NO, Keene CD, Latimer C, Sherfield EE, Van Gelder RD, Ojemann JG, Montine TJ, Darvas M. Flow cytometry analysis of synaptosomes from post-mortem human brain reveals changes specific to Lewy body and Alzheimer's disease. Lab Investig. 2014;94:1161-72.

31. Bai F, Witzmann FA. Synaptosome proteomics. Sub-cellular biochemistry. 2007:43:77-98.

32. Chivet M, Javalet C, Laulagnier K, Blot B, Hemming FJ, Sadoul R. Exosomes secreted by cortical neurons upon glutamatergic synapse activation specifically interact with neurons. J Extracell Vesic. 2014;3:24722.

33. Murray L, Krasnodembskaya AD. Concise review: intercellular communication via organelle transfer in the biology and therapeutic applications of stem cells. Stem cells. 2019;37:14-25.

34. Wang J, Li H, Yao Y, Zhao T, Chen YY, Shen YL, Wang LL, Zhu Y. Stem cell-derived mitochondria transplantation: a novel strategy and the challenges for the treatment of tissue injury. Stem Cell Res Ther. 2018;9:106. 
35. Hough KP, Trevor JL, Strenkowski JG, Wang Y, Chacko BK, Tousif S, Chanda D, Steele C, Antony VB, Dokland T, Ouyang X, Zhang J, Duncan SR, Thannickal VJ, Darley-Usmar VM, Deshane JS. Exosomal transfer of mitochondria from airway myeloid-derived regulatory cells to T cells. Redox biology. 2018;18:54-64.

36. Masuzawa A, Black KM, Pacak CA, Ericsson M, Barnett RJ, Drumm C, Seth P, Bloch DB, Levitsky S, Cowan DB, Mccully JD. Transplantation of autologously derived mitochondria protects the heart from ischemiareperfusion injury. Am J Physiol. 2013;304:H966-82.

37. Chang CY, Liang MZ, Chen L. Current progress of mitochondrial transplantation that promotes neuronal regeneration. Transl Neurodegen. 2019;8:17.

38. Shin B, Cowan DB, Emani SM, Del Nido PJ, McCully JD. Mitochondrial transplantation in myocardial ischemia and reperfusion injury. Adv Exp Med Biol. 2017;982:595-619.
39. Chou SH, Lan J, Esposito E, Ning M, Balaj L, Ji X, Lo EH, Hayakawa K. (Extracellular mitochondria in cerebrospinal fluid and neurological recovery after subarachnoid hemorrhage. Stroke. 2017;48:2231-7.

40. Franklin W, Taglialatela G. A method to determine insulin responsiveness in synaptosomes isolated from frozen brain tissue. J Neurosci Methods. 2016;261:128-34.

41. Provencher SW. CONTIN: a general purpose constrained regularization program for inverting noisy linear algebra and integral equations. Comp Phys Commun. 1982;27:229-42.

\section{Publisher's Note}

Springer Nature remains neutral with regard to jurisdictional claims in published maps and institutional affiliations.
Ready to submit your research? Choose BMC and benefit from:

- fast, convenient online submission

- thorough peer review by experienced researchers in your field

- rapid publication on acceptance

- support for research data, including large and complex data types

- gold Open Access which fosters wider collaboration and increased citations

- maximum visibility for your research: over $100 \mathrm{M}$ website views per year

At BMC, research is always in progress.

Learn more biomedcentral.com/submissions 